\title{
Assessing Change in Avian Influenza A(H7N9) Virus Infections During the Fourth Epidemic — China, September 2015-August 2016
}

\begin{abstract}
Nijuan Xiang, $\mathrm{MD}^{1 *}$; Xiyan Li, MD ${ }^{2 *}$; Ruiqi Ren, $\mathrm{MD}^{1 *}$; Dayan Wang, PhD ${ }^{2}$; Suizan Zhou, $\mathrm{MPH}^{3}$; Carolyn M. Greene, MD³; Ying Song, MD³ $\mathrm{Lei}^{3}$ Zhou, MD ${ }^{1}$; Lei Yang, MD ${ }^{2}$; C. Todd Davis, $\mathrm{PhD}^{3}$; Ye Zhang, MD ${ }^{2}$; Yali Wang, MPH ${ }^{1}$; Jian Zhao, $\mathrm{PhD}^{1}$; Xiaodan Li, MD ${ }^{2}$; A. Danielle Iuliano, PhD ${ }^{3}$; Fiona Havers, $\mathrm{MD}^{3}$; Sonja J. Olsen, $\mathrm{PhD}^{3}$; Timothy M. Uyeki, $\mathrm{MD}^{3}$; Eduardo Azziz-Baumgartner, $\mathrm{MD}^{3}$; Susan Trock, DVM ${ }^{3}$; Bo Liu, MD ${ }^{1}$; Haitian Sui, $\mathrm{MD}^{1}$; Xu Huang ${ }^{1}$; Yanping Zhang, MD ${ }^{1}$; Daxin Ni, MD ${ }^{1}$; Zijian Feng, MD ${ }^{4}$; Yuelong Shu, PhD ${ }^{2}$; Qun Li, MD ${ }^{1}$
\end{abstract}

Since human infections with avian influenza A(H7N9) virus were first reported by the Chinese Center for Disease Control and Prevention (China CDC) in March 2013 (1), mainland China has experienced four influenza A(H7N9) virus epidemics. Prior investigations demonstrated that age and sex distribution, clinical features, and exposure history of $\mathrm{A}(\mathrm{H} 7 \mathrm{~N} 9)$ virus human infections reported during the first three epidemics were similar (2). In this report, epidemiology and virology data from the most recent, fourth epidemic (September 2015August 2016) were compared with those from the three earlier epidemics. Whereas age and sex distribution and exposure history in the fourth epidemic were similar to those in the first three epidemics, the fourth epidemic demonstrated a greater proportion of infected persons living in rural areas, a continued spread of the virus to new areas, and a longer epidemic period. The genetic markers of mammalian adaptation and antiviral resistance remained similar across each epidemic, and viruses from the fourth epidemic remained antigenically well matched to current candidate vaccine viruses. Although there is no evidence of increased human-to-human transmissibility of $\mathrm{A}(\mathrm{H} 7 \mathrm{~N} 9)$ viruses, the continued geographic spread, identification of novel reassortant viruses, and pandemic potential of the virus underscore the importance of rigorous $\mathrm{A}(\mathrm{H} 7 \mathrm{~N} 9)$ virus surveillance and continued risk assessment in China and neighboring countries.

\section{Epidemiology}

As of August 31,2016, mainland China had reported a total of 775 laboratory-confirmed human infections with $\mathrm{A}(\mathrm{H} 7 \mathrm{~N} 9)$ virus from 16 provinces and three municipalities during the four epidemics. In addition, travelers to mainland China accounted for 23 human cases of $\mathrm{A}(\mathrm{H} 7 \mathrm{~N} 9)$ virus infection, including four deaths; these infections were detected in Hong Kong (16 cases), Taiwan (four), Canada (two), and Malaysia (one).

Among 314 counties in China that reported at least one human $\mathrm{A}(\mathrm{H} 7 \mathrm{~N} 9)$ virus infection, 224 (71\%) reported $\leq 2$ infections. Most (83\%) infections were reported in five eastern or southeastern coastal provinces. Whereas most infections in the first epidemic were identified during March-April 2013,

\footnotetext{
*These authors contributed equally to this report.
}

the majority of infections identified in the subsequent three epidemics occurred during November-April of 2013-2014, 2014-2015, and 2015-2016 (Figure).

Among the 775 total reported infections, 659 (85\%) patients reported exposure to live poultry in the 2 weeks preceding illness onset, including live-poultry markets (376 patients, 57\%), backyard poultry $(115,17 \%)$, or both $(120,18 \%)$; and in other settings $(48,7 \%)$ (Table). Median age did not significantly differ between persons infected in the fourth epidemic (58 years) compared with the previous three epidemics (57 years). Twenty-five (3\%) persons reported living with, working with, or having another epidemiologic link to a person infected with influenza $\mathrm{A}(\mathrm{H} 7 \mathrm{~N} 9)$ virus.

Among all 775 infections in the four epidemics, 55 (7\%) were associated with 26 clusters (i.e., at least two epidemiologically linked infections), including 23 clusters of two infections each, and three clusters of three infections each. Most (23, 88\%) clusters included family members only, and three involved nosocomial transmission $(3,4)$. Among the index patients in the 26 clusters, $25(96 \%)$ had a history of live poultry exposure in the 2 weeks before illness onset; secondary infections (29) in clusters resulted from possible human-to-human transmission (18), exposure to a common infectious source (three), or undetermined exposures (eight). The proportion of persons identified within clusters in the fourth epidemic was similar to the proportion in the three previous epidemics combined ( $10 \%$ compared with $7 \%, p=0.16$ ). There was no evidence of tertiary transmission in any cluster.

Fewer A(H7N9) infections were reported during the fourth epidemic ( $n=118$ ) than in the first (134), second (304), or third (219) epidemics. The epidemic period during which persons developed illness in the fourth epidemic (interquartile range $=73$ days) was more than four times as long as that noted during the first epidemic (15 days), twice as long as the second (35 days), and more than one and a half times as long as the third epidemic ( 43 days). More than half of infections in the fourth epidemic were reported from two adjacent provinces located on the southeast coast of China; however, one province (Liaoning) and one municipality (Tianjin City) each reported their first $\mathrm{A}(\mathrm{H} 7 \mathrm{~N} 9)$ virus infection in the fourth epidemic, indicating spread of the virus to new areas. The percentage of $A(\mathrm{H} 7 \mathrm{~N} 9)$ virus-infected persons living in rural areas in the fourth epidemic was higher than in the three previous epidemics combined ( $54 \%$ compared with $42 \%$; $p=0.01$ ). 


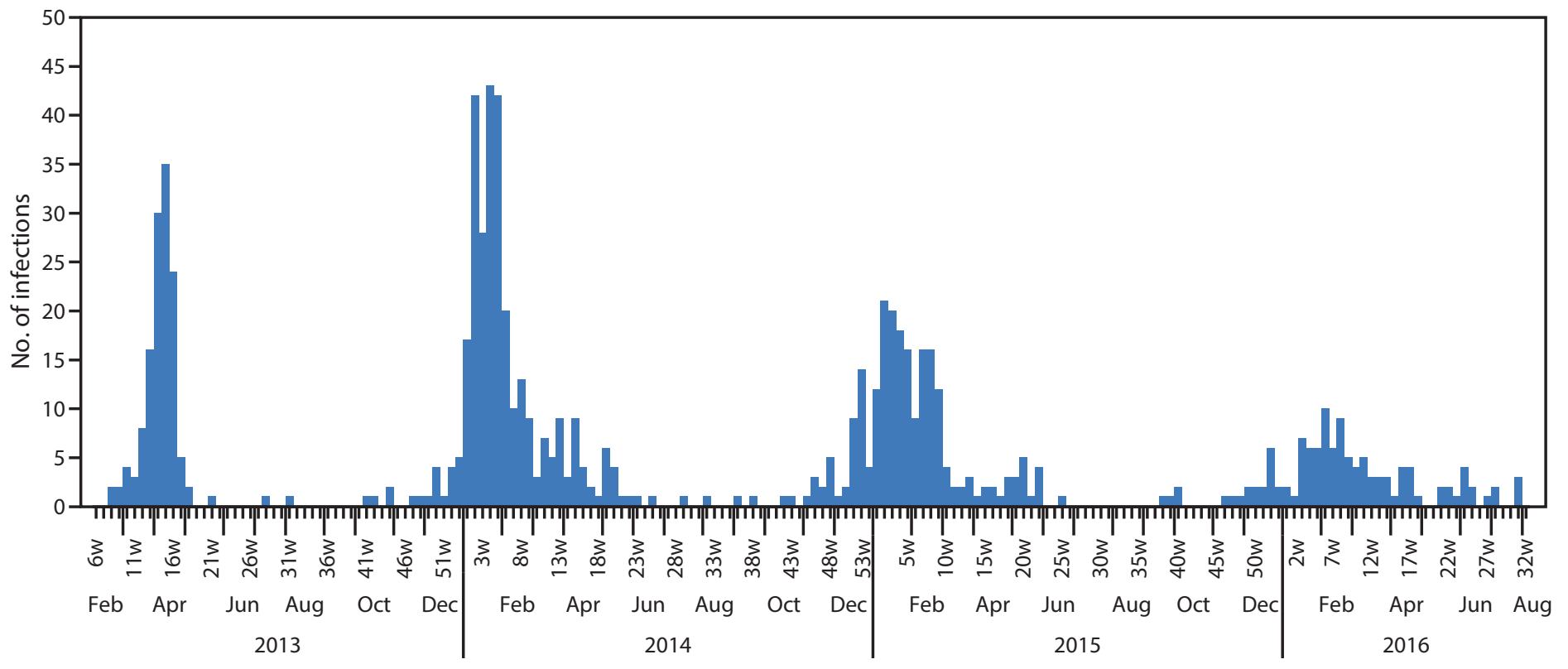

Week of onset

Since April 2013, the Ministry of Agriculture in China has published surveillance data on poultry samples tested for the presence of A(H7N9) virus. As of September 1, 2016, a total of 233 positive samples in 16 provinces were detected. All samples were from live-poultry markets, except one from a farmer's free-range backyard flock.

\section{Clinical Features}

Among the 775 persons with $\mathrm{A}(\mathrm{H} 7 \mathrm{~N} 9)$ infections during the four epidemics, 316 (41\%) died. Among 547 (71\%) patients with data on symptoms available, $95 \%$ (517 of 547) reported fever and $81 \%$ (445 of 547) cough. Fifty-three percent (289 of 545) of patients with medical history data had at least one underlying medical condition (Table). Ninety-one percent (480 of 526) of patients experienced at least one medical complication, including pneumonia, respiratory failure, or acute respiratory distress syndrome (Table); 68\% (358 of 529) were admitted to an intensive care unit (ICU) and $85 \%$ (506 of 592) had severe illness ${ }^{\dagger}$ (Table). The median intervals (interquartile

\footnotetext{
${ }^{\dagger}$ Based on the National Health and Family Planning Commission. Diagnosis and Treatment Protocol of Human Infection with A(H7N9) Avian Influenza Virus (2014 version), 2014.01.26, (http://www.moh.gov.cn/yzygj/s3593g/20 1401/3f69fe196ecb4cfc8a2d6d96182f8b22.shtml), severe illness was defined as an illness with any one of the following: chest radiograph indicative of multilobar lesions or $>50 \%$ increase in size of lesions within a 48 -hour period; dyspnea or respiratory rate $>24$ times per minute for adults; severe hypoxia, defined as $\leq 92 \%$ oxygen saturation while receiving $3-5$ liters of supplemental oxygen per minute; or shock, acute respiratory distress syndrome, or multiple organ dysfunction syndrome.
}

ranges) from illness onset to various medical outcomes ranged from 1 day (onset to first medical encounter) to 17 days (onset to death) (Table).

Although the proportion of patients with severe illness (91\%) in the fourth epidemic was not statistically different from that in the three previous epidemics combined, persons infected in the fourth epidemic were more likely to develop pneumonia $(99 \%$ compared with $87 \%, \mathrm{p}=0.003)$ and be admitted to the ICU $(78 \%$ compared with $66 \%, \mathrm{p}=0.04)$ than were patients in the three previous epidemics (Table). The median interval between illness onset and initial medical consultation, hospitalization, diagnosis, time to antiviral treatment initiation, and death were similar between the fourth and the first three epidemics.

\section{Laboratory Findings}

Since the emergence of $\mathrm{A}(\mathrm{H} 7 \mathrm{~N} 9)$ virus, the majority of viruses from both humans and poultry have contained two hemagglutinin (HA) amino acid residues, $186 \mathrm{~V}$ and 226L/I in $\mathrm{H} 3$ numbering (177 and 217 in $\mathrm{H} 7$ numbering), which are likely to increase human receptor binding (5). During the first three epidemics, the number of A(H7N9) viruses identified in humans retaining the avian receptor binding residues decreased (5). In the fourth epidemic, all $41 \mathrm{~A}(\mathrm{H} 7 \mathrm{~N} 9)$ viruses from humans and 10 from environmental samples contained these two mutations associated with increased human receptor binding (supplemental figure https://stacks.cdc.gov/view/ cdc/42868). The majority of $\mathrm{A}(\mathrm{H} 7 \mathrm{~N} 9)$ viruses isolated from 
TABLE. Number and percentage of patients with reported avian influenza $A(H 7 N 9)$ virus infection $(\mathrm{N}=775)$, by demographic and clinical characteristics and period of illness - mainland China, February 19, 2013-August 31, 2016

\begin{tabular}{|c|c|c|c|}
\hline Characteristic & $\begin{array}{l}\text { Feb 2013-Aug } 2016 \\
\text { Epidemics } 1-4(\mathrm{~N}=775)(\%)\end{array}$ & $\begin{array}{l}\text { Feb 2013-Aug } 2015 \\
\text { Epidemics } 1-3(n=657)(\%)\end{array}$ & $\begin{array}{l}\text { Sep 2015-Aug } 2016 \\
\text { Epidemic } 4(n=118)(\%)\end{array}$ \\
\hline \multicolumn{4}{|l|}{ Age group (yrs) } \\
\hline $0-19$ & $49(6)$ & $47(7)$ & $2(2)$ \\
\hline 20-39 & $122(16)$ & $105(16)$ & $17(14)$ \\
\hline $40-59$ & $269(35)$ & $222(34)$ & $47(40)$ \\
\hline $60-79$ & $291(38)$ & $245(37)$ & $46(39)$ \\
\hline$\geq 80$ & $44(6)$ & $38(6)$ & $6(5)$ \\
\hline Male & $533(69)$ & $456(69)$ & $77(65)$ \\
\hline \multicolumn{4}{|l|}{ Area of residence } \\
\hline City, town, suburb & $438(57)$ & $384(58)$ & $54(46)^{*}$ \\
\hline Countryside, village & $337(43)$ & $273(42)$ & $64(54)$ \\
\hline \multicolumn{4}{|l|}{ Occupation } \\
\hline Farmer & $210(27)$ & $170(26)$ & $40(34)$ \\
\hline Retiree & $184(24)$ & $162(25)$ & $22(19)$ \\
\hline Homemaker or unemployed & $91(12)$ & $72(11)$ & $19(16)$ \\
\hline Other occupations ${ }^{\dagger}$ & $290(37)$ & $253(39)$ & $37(31)$ \\
\hline Live poultry exposure, $\mathrm{N}, \mathrm{n} / \mathrm{N}$ & $659(85)$ & $558(85)$ & $101(86)$ \\
\hline LPM or poultry from LPM & $376 / 659(57)$ & $321 / 558(58)$ & $55 / 101(54)$ \\
\hline Household poultry & $115 / 659(17)$ & $97 / 558(17)$ & 18/101 (18) \\
\hline LPMs and household poultry & $120 / 659(18)$ & 98/558 (18) & $22 / 101(22)$ \\
\hline Other settings (e.g., neighboring backyard poultry farms) & $48 / 659(7)$ & $42 / 558(8)$ & $6 / 101(6)$ \\
\hline Severe illness, \$ n/N & $506 / 592(85)$ & $431 / 510(85)$ & $75 / 82(91)$ \\
\hline Deaths, $N$ & $316(41)$ & $271(41)$ & $45(38)$ \\
\hline \multicolumn{4}{|l|}{ Main early symptoms, $n / N$} \\
\hline Fever & $517 / 547(95)$ & $444 / 471(94)$ & $73 / 76(96)$ \\
\hline Cough & $445 / 547(81)$ & $385 / 471(82)$ & $60 / 76(79)$ \\
\hline Sore throat & $107 / 547(20)$ & $94 / 471(20)$ & $13 / 76(17)$ \\
\hline Weakness & $218 / 547(40)$ & $185 / 471(39)$ & $33 / 76(43)$ \\
\hline Sore muscles & $124 / 547(23)$ & $107 / 471(23)$ & $17 / 76(22)$ \\
\hline Underlying medical conditions, $\mathrm{n} / \mathrm{N}$ & $289 / 545(53)$ & $241 / 469(51)$ & $48 / 76(63)$ \\
\hline $\begin{array}{l}\text { Cardiovascular/cerebrovascular disease (including } \\
\text { isolated hypertension) }\end{array}$ & $187 / 545(34)$ & $159 / 469(34)$ & $28 / 76(37)$ \\
\hline Metabolic diseases & $84 / 545(15)$ & $68 / 469(14)$ & $16 / 76(21)$ \\
\hline Chronic lung disease & $63 / 545(12)$ & $50 / 469(11)$ & $13 / 76(17)$ \\
\hline Chronic liver diseases & $37 / 545(7)$ & $32 / 469(7)$ & $5 / 76(7)$ \\
\hline Hematological diseases & $16 / 545(3)$ & $14 / 469(3)$ & $2 / 76(3)$ \\
\hline Cancer & $14 / 545(3)$ & $9 / 469(2)$ & $5 / 76(7)^{*}$ \\
\hline Rheumatic autoimmune disease & $12 / 545(2)$ & $11 / 469(2)$ & $1 / 76(1)$ \\
\hline Chronic kidney diseases & $18 / 545(3)$ & $16 / 469(3)$ & $2 / 76(3)$ \\
\hline Antiviral treatment & $481 / 529(91)$ & $412 / 453(91)$ & $69 / 76(91)$ \\
\hline Received antivirals $\leq 48$ hours after symptom onset & $54 / 476(11)$ & $49 / 412(12)$ & $5 / 64(8)$ \\
\hline Admitted to intensive care unit, $n / N$ & $358 / 529(68)$ & $299 / 453(66)$ & $59 / 76(78)^{*}$ \\
\hline Complications, n/N & $480 / 526(91)$ & $405 / 451(90)$ & $75 / 75(100)^{*}$ \\
\hline Pneumonia & $465 / 526(88)$ & $391 / 451(87)$ & $74 / 75(99)^{*}$ \\
\hline Respiratory failure & $369 / 526(70)$ & $310 / 451(69)$ & $59 / 75(79)$ \\
\hline Acute respiratory distress syndrome & $352 / 526(67)$ & $297 / 451(66)$ & $55 / 75(73)$ \\
\hline Hepatic insufficiency & $223 / 526(42)$ & $192 / 451(43)$ & $31 / 75(41)$ \\
\hline Renal insufficiency & $180 / 526(34)$ & $151 / 451(33)$ & 29/75 (39) \\
\hline Septic shock & $167 / 526(32)$ & $140 / 451(31)$ & $27 / 75(36)$ \\
\hline Cardiac failure & $146 / 526(28)$ & $124 / 451(27)$ & $22 / 75(29)$ \\
\hline Disseminated intravascular coaqulation & $29 / 526(6)$ & $25 / 451(6)$ & $4 / 75(5)$ \\
\hline
\end{tabular}

See table footnotes on next page.

patients in each epidemic carried the PB2-627K mutation, which has been associated with mammalian adaptation. This mutation was found in $68 \%$ (62 of 91) of viruses in the first epidemic, $79 \%$ (122 of 154) in the second, $62 \%$ (52 of 84) in the third, and $71 \%$ (29 of 41$)$ in the fourth epidemic. Almost all A(H7N9) viruses isolated from birds and humans had PB1-368V, which might also enhance $\mathrm{A}(\mathrm{H} 7 \mathrm{~N} 9)$ virus transmission to humans (5).
Among the $391 \mathrm{~A}(\mathrm{H} 7 \mathrm{~N} 9)$ viruses isolated from humans that were tested for the presence of substitutions associated with reduced sensitivity to neuraminidase (NA) inhibitors, only 16 (4\%) possessed these substitutions in the NA protein: E119V (four), A246T (one), or R292K (11). These mutations were not identified in $498 \mathrm{~A}(\mathrm{H} 7 \mathrm{~N} 9)$ viruses sampled from birds or the environment, suggesting the mutations occurred during 
Morbidity and Mortality Weekly Report

TABLE. (Continued) Number and percentage of patients with reported avian influenza $A(H 7 N 9)$ virus infection ( $N=775)$, by demographic and clinical characteristics and period of illness - mainland China, February 19, 2013-August 31, 2016

\begin{tabular}{|c|c|c|c|}
\hline Characteristic & $\begin{array}{c}\text { Feb 2013-Aug } 2016 \\
\text { Epidemics } 1-4(\mathrm{~N}=775)(\%)\end{array}$ & $\begin{array}{c}\text { Feb 2013-Aug } 2015 \\
\text { Epidemics } 1-3(n=657)(\%)\end{array}$ & $\begin{array}{c}\text { Sep 2015-Aug } 2016 \\
\text { Epidemic } 4(n=118)(\%)\end{array}$ \\
\hline \multicolumn{4}{|l|}{ Interval, median days (IQR) } \\
\hline Onset to first clinic visit & $1(0-4)$ & $1(0-4)$ & $2(0-5)$ \\
\hline Onset to first hospitalization & $4(3-7)$ & $4(3-7)$ & $4(3-6)$ \\
\hline Onset to diagnosis & $8(6-11)$ & $9(6-11)$ & $8(6-11)$ \\
\hline Onset to starting anti-viral treatment & $6(4-8)$ & $6(4-8)$ & $6(5-7)$ \\
\hline Onset to death & $17(10-28)$ & $17(10-30)$ & $15(8-24)$ \\
\hline
\end{tabular}

Abbreviations: $\mathrm{IQR}=$ interquartile range; $\mathrm{LPM}=$ live-poultry market.

* Significant difference between Epidemic 4 and Epidemics 1-3 $(p<0.05)$.

† Other occupations include laborers, persons working in government or government-affiliated institutions, business service providers, children, and students.

$\S$ Illness with any one of following: chest radiograph indicative of multilobar lesions or $>50 \%$ increase in size of lesions within a 48 -hour period; dyspnea or respiratory rate $>24$ times per minute for adults; severe hypoxia defined as $<92 \%$ oxygen saturation while receiving $3-5$ liters of supplemental oxygen per minute; or shock, acute respiratory distress syndrome, or multiple organ dysfunction syndrome.

human infection or as a result of antiviral drug treatment. Antigenic analysis of viruses from all four epidemics showed that viruses were well inhibited by postinfection ferret antisera raised against the candidate vaccine virus, $\mathrm{A} / \mathrm{Anh}$ ui/1/2013, indicating that recent $\mathrm{A}(\mathrm{H} 7 \mathrm{~N} 9)$ viruses remain antigenically well matched to current candidate vaccine viruses (5). Reassortment with $\mathrm{A}(\mathrm{H} 9 \mathrm{~N} 2)$ virus internal genes continues to be detected, which might mediate future host adaptation and interspecies transmission of $\mathrm{A}(\mathrm{H} 7 \mathrm{~N} 9)$ virus (G).

\section{Discussion}

Many characteristics and clinical features of human infections with influenza $A(\mathrm{H} 7 \mathrm{~N} 9)$ virus in China reported during the fourth epidemic (September 2015-August 2016) were similar to those in the previous three epidemics since 2013, including age and sex distribution, and exposure history. However, during the fourth epidemic, infections continued to be reported from areas that had not reported infections in the past, a higher proportion of infected persons lived in rural areas, and a higher percentage of patients required ICU admission. In addition, the duration of the epidemic has been increasing each year.

Viruses collected from both humans and environmental samples from the fourth epidemic showed few genetic changes in the HA and NA genes compared with viruses from earlier epidemics. Although genetic markers of mammalian adaptation continue to be identified in viral polymerase genes, their frequency remains consistent across each epidemic. Few antigenic differences were identified between the viruses from the fourth epidemic and vaccine strains available for manufacturing, suggesting that recently circulating viruses remain antigenically well matched to currently developed candidate vaccine viruses. As the $\mathrm{A}(\mathrm{H} 7 \mathrm{~N} 9)$ epidemic season occurs during China's winter seasonal influenza peak, ongoing viral genome risk assessment is needed to monitor mutations and reassortment.
Since 2013, local governments have implemented numerous prevention and control measures, including temporary closure of live-poultry markets and disinfection protocols, which have decreased the prevalence of $\mathrm{A}(\mathrm{H} 7 \mathrm{~N} 9)$ virus in live-poultry market environments $(7,8)$. However, because the $\mathrm{A}(\mathrm{H} 7 \mathrm{~N} 9)$ virus is a low pathogenic avian influenza virus and infections in poultry are subclinical, identifying when the virus is spreading among poultry or when humans might be at risk for infection is challenging. The continued identification of the virus in new areas highlights the need for a national containment-controleradication program in poultry.

The findings in this report are subject to at least three limitations. First, although fewer infections were reported during the fourth epidemic than the first three, the percentages of patients who developed pneumonia and were admitted to the ICU were higher. It is possible that this observed increase in clinical severity in the fourth epidemic represents a surveillance artifact. Several provinces with the highest prevalence of human $\mathrm{A}(\mathrm{H} 7 \mathrm{~N} 9)$ virus infections recently established provincial pneumonia surveillance systems, which might have increased identification and reporting of pneumonia in persons with $\mathrm{A}(\mathrm{H} 7 \mathrm{~N} 9)$ virus infection. In addition, mild illnesses might be less likely to be detected (9) as concern about $\mathrm{A}(\mathrm{H} 7 \mathrm{~N} 9)$ virus as a public health threat declined over time, possibly leading to a decrease in identification and reporting of less severe infections. Further, as more infections occur in rural areas with fewer health care resources, there might be less ability to both identify and promptly treat persons before they develop severe illness. Second, data on medical history, illness presentation, and clinical course were missing for nearly one third of all persons with infections. Finally, for all four epidemics, self-reported exposure history was subject to recall bias.

There is no evidence of increased transmissibility of $\mathrm{A}(\mathrm{H} 7 \mathrm{~N} 9)$ virus from poultry or environmental exposures to humans in China or sustained human-to-human transmission; however, using the Influenza Risk Assessment Tool (10), CDC 


\section{Summary}

What is already known about this topic?

Influenza $A(H 7 N 9)$ virus is a low pathogenic avian influenza virus that can cause severe illness in humans, with a case-fatality rate of 40\%. Since March 2013, China has experienced four annual avian influenza $A(H 7 N 9)$ virus epidemics with human infections. Most human infections have been associated with exposure to live poultry, particularly in live-poultry markets. In the first three annual epidemics, there was no evidence of sustained human-to-human transmission.

What is added by this report?

Epidemiology and virology data from the most recent (fourth) epidemic, September 2015-August 2016, suggest no evidence of increased transmissibility of $A(H 7 N 9)$ virus from poultry or environmental exposures to humans or of sustained human-tohuman transmission. Characteristics of the fourth epidemic included greater percentages of patients admitted to intensive care units and with diagnoses of pneumonia, identification of the virus in new areas, a greater percentage of infected persons living in rural areas, and a longer epidemic period. Genetic changes in the virus have not been sufficient to alter antigenic properties or cause mismatch with candidate vaccines.

What are the implications for public health practice?

There is a need for a national containment-control-eradication program in poultry, in addition to effective $A(H 7 N 9)$ virus surveillance and continued risk assessment among humans and poultry in China and neighboring countries.

found that $\mathrm{A}(\mathrm{H} 7 \mathrm{~N} 9)$ virus has the highest potential pandemic risk of any novel influenza $A$ viruses that have been assessed. The recent geographic spread, the identification of divergent virus lineages, and the pandemic potential of the virus underscore the importance of effective $\mathrm{A}(\mathrm{H} 7 \mathrm{~N} 9)$ virus surveillance and continued risk assessment among humans and poultry in China and neighboring countries.

\section{Acknowledgments}

Provincial, municipal and local CDCs and designated hospitals in Zhejiang, Guangdong, Jiangsu, Shanghai, Hunan, Fujian, Anhui, Jiangxi, Beijing, Shandong, Henan, Xinjiang, Guangxi, Jilin, Guizhou, Hebei, Hubei, Liaoning, and Tianjin.

\begin{abstract}
${ }^{1}$ Public Health Emergency Center, Chinese Center for Disease Control and Prevention, Beijing; ${ }^{2}$ Chinese National Influenza Center, National Institute for Viral Disease Control and Prevention, Collaboration Innovation Center for Diagnosis and Treatment of Infectious Diseases, Chinese Center for Disease Control and Prevention; Key Laboratory for Medical Virology, National Health and Family Planning Commission, Beijing; ${ }^{3}$ Influenza Division, National Center for Immunization and Respiratory Diseases, CDC; ${ }^{4}$ Chinese Center for Disease Control and Prevention, Beijing.
\end{abstract}

Corresponding author: Qun Li, liqun@chinacdc.cn, 86-10-58900545.

\section{References}

1. Gao R, Cao B, Hu Y, et al. Human infection with a novel avian-origin influenza A (H7N9) virus. N Engl J Med 2013;368:1888-97. http:// dx.doi.org/10.1056/NEJMoa1304459

2. Xiang N, Iuliano AD, Zhang Y, et al. Comparison of the first three waves of avian influenza $A(H 7 N 9)$ virus circulation in the mainland of the People's Republic ofChina. BMC Infect Dis 2016;16:734. http://dx.doi.org/10.1186/ s12879-016-2049-2

3. Chen H, Liu S, Liu J, et al. Nosocomial co-transmission of avian influenza $\mathrm{A}(\mathrm{H} 7 \mathrm{~N} 9)$ and $\mathrm{A}(\mathrm{H} 1 \mathrm{~N} 1) \mathrm{pdm} 09$ viruses between 2 patients with hematologic disorders. Emerg Infect Dis 2016;22:598-607. http:// dx.doi.org/10.3201/eid2204.151561

4. Fang CF, Ma MJ, Zhan BD, et al. Nosocomial transmission of avian influenza A (H7N9) virus in China: epidemiological investigation. BMJ 2015;351:h5765. http://dx.doi.org/10.1136/bmj.h5765

5. Wang D, Yang L, Zhu W, et al. Two outbreak sources of influenza A(H7N9) viruses have been established in China. J Virol 2016;90:5561-73. http:// dx.doi.org/10.1128/JVI.03173-15

6. Wang D, Yang L, Gao R, et al. Genetic tuning of the novel avian influenza $\mathrm{A}(\mathrm{H} 7 \mathrm{~N} 9)$ virus during interspecies transmission, China, 2013. Euro Surveill 2014;19:20836. http://dx.doi.org/10.2807/1560-7917. ES2014.19.25.20836

7. Kang M, He J, Song T, et al. Environmental sampling for avian influenza $\mathrm{A}(\mathrm{H} 7 \mathrm{~N}$ 9) in live-poultry markets in Guangdong, China. PLoS One 2015;10:e0126335.

8. Wang X, Liu S, Mao H, Yu Z, Chen E, Chai C. Surveillance of avian $\mathrm{H} 7 \mathrm{~N} 9$ virus in various environments of Zhejiang Province, China before and after live poultry markets were closed in 2013-2014. PLoS One 2015;10:e0135718. http://dx.doi.org/10.1371/journal.pone.0135718

9. Qin Y, Horby PW, Tsang TK, et al. Differences in the epidemiology of human cases of avian influenza $\mathrm{A}(\mathrm{H} 7 \mathrm{~N} 9)$ and $\mathrm{A}(\mathrm{H} 5 \mathrm{~N} 1)$ viruses infection. Clin Infect Dis 2015;61:563-71. http://dx.doi.org/10.1093/cid/civ345

10. CDC. Influenza Risk Assessment Tool (IRAT). Atlanta, GA: US Department of Health and Human Services, CDC; 2016. http://www. cdc.gov/flu/pandemic-resources/tools/risk-assessment.htm 